\title{
First Isolation of Enantiopure Perfluoroalkylated Sulfilimines and Sulfoximines
}

\author{
Thanh-Nghi Le ${ }^{\mathrm{ab}}$, Emilie Kolodziej ${ }^{\mathrm{b}}$, Patrick Diter ${ }^{\mathrm{a}}$, Bruce Pégot ${ }^{\mathrm{a}}$, Chloée Bournaud ${ }^{\mathrm{b}}$, Martial Toffano ${ }^{\mathrm{b}}$, \\ Régis Guilot ${ }^{\mathrm{b}}$, Giang Vo-Thanhb, and Emmanuel Magnier*a
}

\begin{abstract}
Mono-, di- and trifluoromethyl sulfilimines and sulfoximines have been isolated for the first time in enantiopure form by separation of the racemate by supercritical fluid chromatography. The electrophilic trifluoromethylating Shibata reagent has been prepared as a single enantiomer.
\end{abstract}

Keywords: Enantiomers · Fluorine · SFC · Sulfilimines · Sulfoximines

\section{Introduction}

Sulfilimines and sulfoximines, which contain a stereogenic sulfur (IV) or (VI) center respectively, are very particular substrate classes in organic chemistry. Numerous studies have demonstrated their relevance as ligands for catalysis or as chiral auxiliaries. ${ }^{[1,2]}$ Their introduction for life sciences purposes, namely in medicinal chemistry or crop protection, is furthermore an emerging and promising domain. ${ }^{[3]}$ This increased interest for these moieties has been facilitated by the major progress realized in their synthesis. Efficient, safe and metal-free preparative methods have been published in recent years and have made them easily accessible, including in particular their enantiomeric form. ${ }^{[1,4]}$ The fluorinated version of such functions, i.e. with a perfluoroalkyl chain attached to the sulfur atom, is a very unusual member of this family. Their synthesis has indeed been restricted for a long time to a small number of targets and to very tedious methodologies.
In recent years, a pronounced revival of the chemistry of fluorinated sulfilimines and sulfoximines has appeared. They have been identified as versatile perfluoroalkylating reagents (as source of radical, electrophilic and nucleophilic fluorinated entities) ${ }^{[5]}$ and our group (vide infra) along with others have improved their synthesis but only for racemic versions. ${ }^{[6]}$ Examples of enantiopure fluorinated sulfur (IV) or (vI) molecules reported in literature are very scare. To the best of our knowledge, there are only four articles which refer to the preparation and the use of enantiopure monofluoro $^{[7]}$ - and difluoromethyl ${ }^{[8]}$ sulfoximines. These optically pure compounds have always been constructed by late fluorination of the corresponding enantiopure sulfoximines. Furthermore, no enantiomerically pure trifluoromethylated sulfilimine or sulfoximine has been described so far. In this context, the development of highly stereoselective synthesis of perfluoroalkylated sulfoximines is still a challenge.

In this article, we describe our work devoted to the preparation of optically enriched sulfur derivatives with emphasis on perfluoroalkylated sulfilimine and sulfoximine.

\section{Result and Discussion}

Our group has recently unlocked the access of various perfluoroalkylated aryl sulfoximines 3 starting from fluorinated sulfoxides $\mathbf{1}$ via sulfilimine intermediates 2 (Scheme 1). Variations of the aromatic substituents (electron-donating and electron-withdrawing groups), and of the fluorinated chain (monofluoro- to perfluoroalkyl chains) were feasible.[5e] Our versatile methodology allowed the straightforward synthesis of a wide range of racemic perfluoroalkyl sulfur (IV) and (VI) compounds.

In our quest for the preparation of optically active fluorinated sulfilimines and sulfoximines, we were wondering if the key step of our methodology, the formation of sulfilimine, could be realized without racemization of the sulfur center. To test this hypothesis, synthesis of perfluoroalkylated sulfoxides of pure optical form was therefore a first requirement. The only examples of fluorinated chiral sulfur (IV) arylsulfinylacetic acids ( $\mathrm{RS}(\mathrm{O})$ $\mathrm{CF}_{2} \mathrm{COOH}$ ) were described by Yagupolskii et al. $^{29]}$ They were obtained by crystallization of diastereomers with $(R)-(+)-$ methylbenzylamine. Several methods have nevertheless been reported for the highly stereoselective synthesis of alkylated sulfoxides, ${ }^{[10]}$ but they were never applied to fluorinated series. One of the most efficient conventional approaches for the stereoselective synthesis of sulfoxides is the asymmetric oxidation by an hydroperoxide in the presence of a stoichiometric or catalytic amount of a chiral tetra-isopropoxide titanium complex bearing tartrate ligands following Kagan's ${ }^{[11]}$ or Modena's ${ }^{[12]}$ protocols. Unfortunately all the attempts with

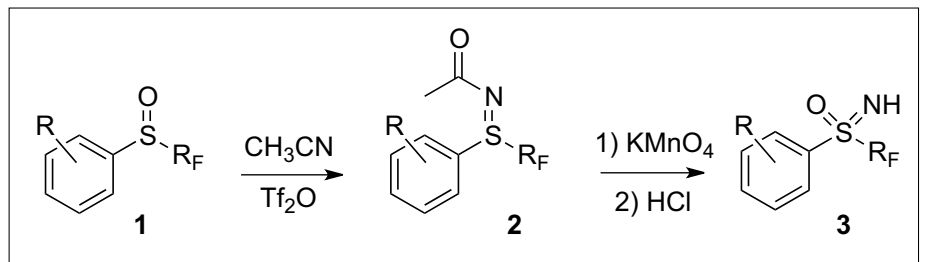

Scheme 1.

Straightforward synthesis of perfluoroalkylated sulfilimines and sulfoximines. 
fluorinated sulfides by these methods have led only to the formation of a racemic mixture of sulfoxides in very low yield (13\%). We assumed that the tamed reactivity of the non-bonding electrons of the sulfur, due to the presence of the fluorine atoms, could account for this result. Nucleophilic substitution is one of the other main strategies usually explored. For this reaction, we used the Andersen sulfinate ${ }^{[13]}$ which usually reacts with nucleophiles through total inversion of configuration. However, though the reaction of menthyl $(S)-p$ tolylsulfinate with Ruppert-Prakash reagent $\mathrm{CF}_{3} \mathrm{SiMe}_{3}$, ${ }^{[14]}$ initiated by menthyl alkoxide or fluorine anion, was acceptable in terms of conversion, it gave rise only to racemic $p$-tolyltrifluoromethylsulfoxide (Scheme 2). The use of other fluorinated nucleophiles $\left(\mathrm{C}_{2} \mathrm{~F}_{5} \mathrm{SiMe}_{3}, \mathrm{C}_{6} \mathrm{~F}_{13} \mathrm{MgBr}\right)$ or chiral sulfinate ${ }^{[15]}$ cannot change the total lack of enantioselectivity for the nucleophilic substitution. The racemization of the sulfur center of chiral sulfinates has already been reported in nucleophilic substitutions with lithium nucleophiles ${ }^{[16]}$ or in acidic conditions, ${ }^{[17]}$ but never with fluorinated nucleophiles. Faced with these quite disappointing results, we next turned our attention to the oxidation step of sulfilimines. As these compounds are oxidized into sulfoximines by the relatively mild potassium permanganate reagent, we envisioned the possibility to develop oxidative chiral resolution. ${ }^{[18]}$ Unfortunately kinetic resolution for this last oxidation with the Kagan's reagent proved inefficient as no conversion occurred.

Gais and coworkers ${ }^{[19]}$ described the separation of a racemic mixture of methylphenylsulfoximine by crystallization with 0.5 equiv of (-)-10-camphorsulfonic acid in acetone. Both enantiomers were separated in good yield and enantiomeric excess, after basic hydrolysis. The same operation with a racemic mixture of trifluoromethylphenylsulfoximine does not allow any crystallization of diastereoisomeric salts. We assumed that the nitrogen atom of the sulfoximine was not basic enough to react with the camphorsulfonic acid. Other chiral acids were tested but without further success.

At this stage of our studies, reliable chiral separation methods became necessary to assess the stereochemical integrity of enantiomers as well as to examine the potential for interconversion of individual stereoisomers. In a first approach, all the chiral sulfur derivatives (sulfoxides, sulfilimines and sulfoximines) were analytically separated by high performance liquid chromatography (HPLC) showing that it is possible to differentiate these chiral compounds. ${ }^{[20]}$ The clear separation of signals for each enantiomer proves that there is no rapid equilibrium between each enantio-

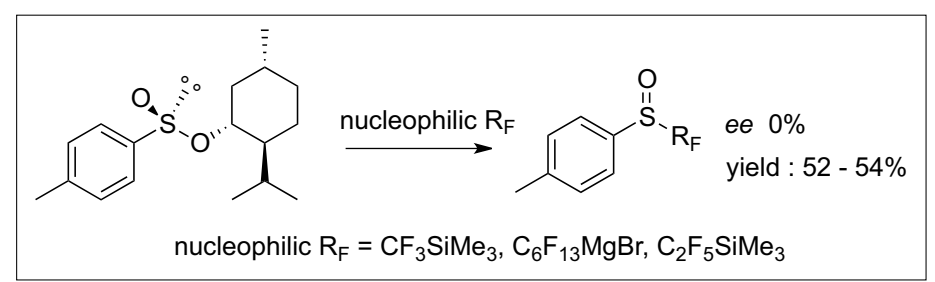

Scheme 2. Attempts of enantioselective synthesis of fluorinated sulfoxides. mer of sulfoxides or of sulfoximines. The next step was the adaption of this analytical method to a preparative one, to check the feasibility of the separation and the enantiomeric stability. Another technique has shown a high ability for the separation of enantiomer on chiral phase: supercritical fluid chromatography (SFC). ${ }^{[21]}$ Generally the results obtained from HPLC are easily transposable. Although the chiral column Chiralpak IA at our disposal was not adapted to the separation of fluorinated sulfoxides, it was hoped that this would not be the case for the sulfilimines. To our delight, we succeeded in the separation of the two enantiomers of sulfilimine 5 using 20\% methanol as the co-solvent with carbon dioxide (Scheme 3).[22] This procedure gave us the enantiomers $5 \mathbf{a}$ and $\mathbf{5 b}$ which are fully separated. Each stereoisomer was afterwards oxidized to produce the corresponding sulfoximines $\mathbf{6 a}$ and $\mathbf{6 b}$. Their enantiomeric purity was secured by chiral HPLC analysis. We were pleased to confirm that the oxidation proceeded with retention of relative configuration.

Compounds $6 \mathbf{a}$ and $\mathbf{6 b}$ were stored for two months at room temperature on the bench and their enantiomeric stability was confirmed by HPLC measurements. After this period, no erosion of the enantiomeric excess had been detected. Lastly, the absolute configurations of the trifluoromethyl sulfilimines $\mathbf{5 a}$ and sulfoximines $\mathbf{6 a}$ were attributed without any ambiguity by X-ray analysis (Fig. 1).[23]

We then extended our separation protocol by SFC to some other fluoroalkylated dichlorofluoromethyl- and bromodifluoromethyl sulfoximines $\mathbf{7}$ and $\mathbf{8}$ was separated (entries 3 to 6 ) and independently transformed into their corresponding sulfur (vI) derivatives. The enantiomeric purity of each sulfoximine $9 \mathbf{a}, \mathbf{b}$ and $\mathbf{1 0 a}, \mathbf{b}$ was ensured by analytical SCF or HPLC. Table 1 summarizes the optical rotation of the 12 enantiomers obtained in our study. The absolute configuration of the monofluoroand difluoromethyl sulfur derivatives was attributed by analogy with the data (retention time and X-ray analysis) collected for the trifluoromethyl series.

The first isolation of the trifluoromethyl phenyl sulfoximine $\mathbf{6 b}$ strongly encouraged us to prepare an enantiomerically pure version of Shibata's reagent 12 (Scheme 4). Compound $\mathbf{6 b}$ was thus transformed into the electrophilic perfluoroalkylating agent 12-(S) following the same procedure as described for the racemic reagent.[5b] The absolute configuration of compounds 11 and 12 was confirmed thanks to the optical data (Table 1).

We then examined the reaction of this chiral electrophilic trifluoromethylating reagent with $\beta$-keto ester $\mathbf{1 3}$ as nucleophile, under standard conditions as described by compounds (Table 1). Each enantiomer of

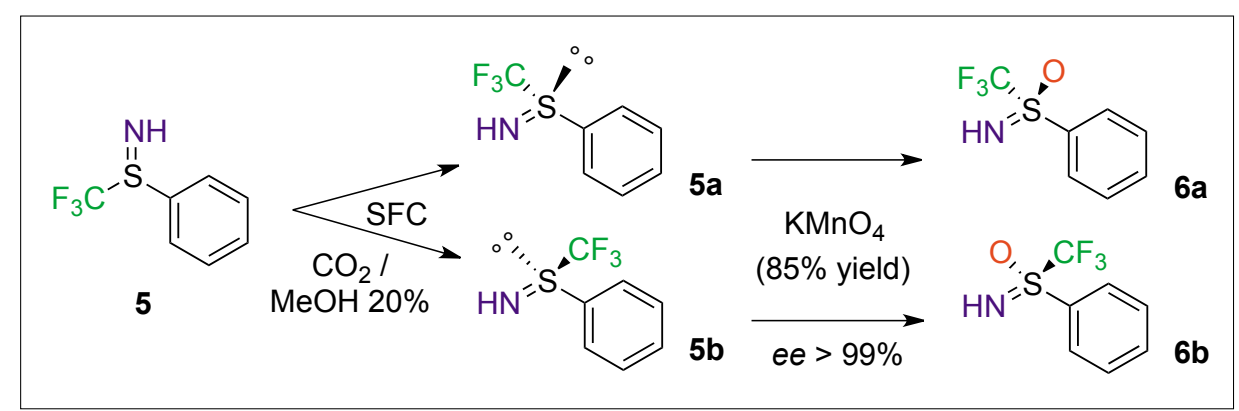

Scheme 3. Separation of enantiomers of sulfilimines and transformation into sulfoximines.

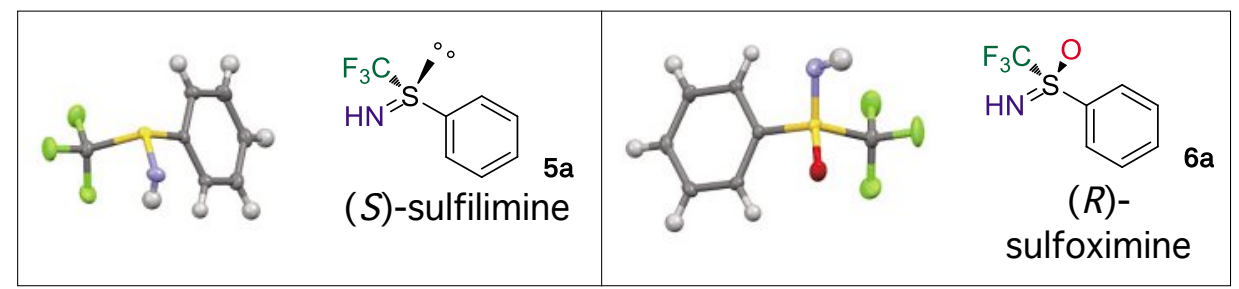

Fig. 1. X-ray structures of enantiopure sulfilimine $\mathbf{5 a}$ and sulfoxime $\mathbf{6 a}$. 
Table 1: Optical rotation data for sulfilimines and sulfoximines.

\begin{tabular}{|c|c|c|c|c|c|c|c|c|}
\hline Entry & Cpd & $\mathbf{R}_{\mathbf{F}}$ & $\mathbf{R}$ & $\mathbf{n}$ & c $[\mathrm{g} / \mathrm{mL}]$ & Solvent & {$[\mathbf{a}]_{\mathbf{D}}{ }^{20 \mathbf{a}}$} & Config. \\
\hline 1 & $5 \mathbf{a}$ & $\mathrm{CF}_{3}$ & $\mathrm{H}$ & 0 & 0.0113 & $\mathrm{CH}_{2} \mathrm{Cl}_{2}$ & +89.6 & $(S)^{\mathbf{b}}$ \\
\hline 2 & $5 b$ & $\mathrm{CF}_{3}$ & $\mathrm{H}$ & 0 & 0.0112 & $\mathrm{CH}_{2} \mathrm{Cl}_{2}$ & -88.3 & $(R)^{\mathbf{b}}$ \\
\hline 3 & $7 \mathbf{a}$ & $\mathrm{CFCl}_{2}$ & Ac & 0 & 0.0303 & acetone & +45.0 & $(S)^{\mathbf{c}}$ \\
\hline 4 & $7 b$ & $\mathrm{CFCl}_{2}$ & Ac & 0 & 0.0302 & acetone & -44.9 & $(R)^{\mathbf{c}}$ \\
\hline 5 & $8 \mathbf{a}$ & $\mathrm{CF}_{2} \mathrm{Br}$ & Ac & 0 & 0.0445 & acetone & +22.7 & $(S)^{\mathbf{c}}$ \\
\hline 6 & $8 b$ & $\mathrm{CF}_{2} \mathrm{Br}$ & Ac & 0 & 0.0453 & acetone & -23.0 & $(R)^{\mathbf{c}}$ \\
\hline 7 & $6 \mathbf{a}$ & $\mathrm{CF}_{3}$ & $\mathrm{H}$ & 1 & 0.0229 & $\mathrm{CH}_{2} \mathrm{Cl}_{2}$ & +16.6 & $(R)^{\mathbf{b}}$ \\
\hline 8 & $6 b$ & $\mathrm{CF}_{3}$ & $\mathrm{H}$ & 1 & 0.0223 & $\mathrm{CH}_{2} \mathrm{Cl}_{2}$ & -16.3 & $(S)^{\mathbf{b}}$ \\
\hline 9 & $9 \mathbf{a}$ & $\mathrm{CFCl}_{2}$ & $\mathrm{H}$ & 1 & 0.0151 & acetone & +4.6 & $(R)^{\mathbf{c}}$ \\
\hline 10 & $9 b$ & $\mathrm{CFCl}_{2}$ & $\mathrm{H}$ & 1 & 0.0138 & acetone & -4.8 & $(S)^{\mathbf{c}}$ \\
\hline 11 & $10 a$ & $\mathrm{CF}_{2} \mathrm{Br}$ & $\mathrm{H}$ & 1 & 0.0178 & acetone & +3.9 & $(R)^{\mathbf{c}}$ \\
\hline 12 & $10 b$ & $\mathrm{CF}_{2} \mathrm{Br}$ & $\mathrm{H}$ & 1 & 0.0177 & acetone & -3.8 & $(S)^{\mathbf{c}}$ \\
\hline 13 & 11 & $\mathrm{CF}_{3}$ & $\mathrm{Me}$ & 1 & 0.0311 & acetone & -22.1 & $(S)^{\mathbf{c}}$ \\
\hline 14 & 12 & $\mathrm{CF}_{3}$ & $(\mathrm{Me})_{2}$ & 1 & 0.0150 & $\mathrm{CHCl}_{3}$ & -3.5 & $(S)^{\mathbf{c}}$ \\
\hline
\end{tabular}

${ }^{\mathrm{a}}[\alpha]_{D}^{20}$ were measured for wavelength $\lambda=589 \mathrm{~nm}$ at $20{ }^{\circ} \mathrm{C}$. ${ }^{\mathrm{b}}$ The absolute configuration was determined by X-ray. ${ }^{\circ}$ The absolute configuration was deduced by analogy of the $\mathrm{X}$-ray results.

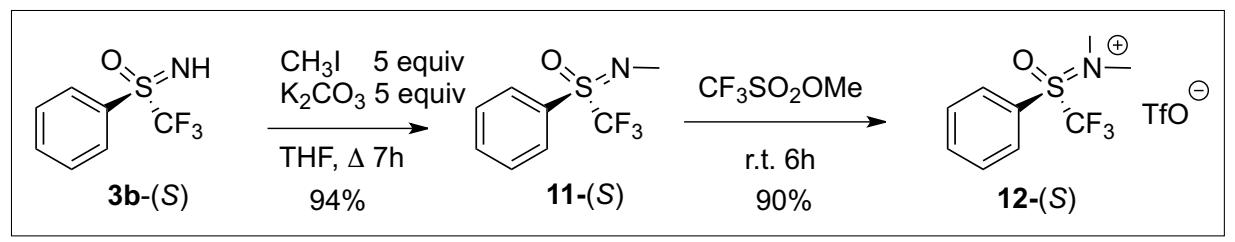

Scheme 4. First preparation of Shibata reagent as a single enantiomer.

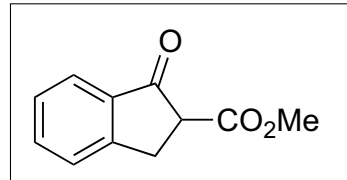

13

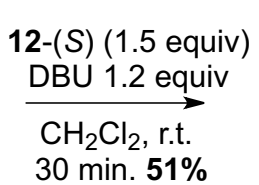

$30 \min . \mathbf{5 1 \%}$

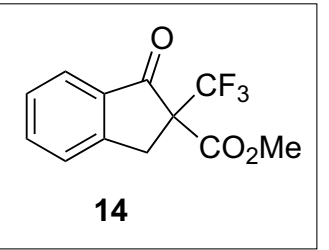

Scheme 5.

Electrophilic trifluoromethylation of $\beta$-ketoester with reagent 12-(S).
Shibata (Scheme 5). In this preliminary result, we found that the salt 12 reacted with indanone carboxylate $\mathbf{1 3}$ in the presence of BDU to yield trifluoromethylated compound 14 in racemic form.

As the mechanism pathway of this trifluoromethylation reaction is not clear, further investigations are needed to provide useful insights into the understanding of this result and to be able to propose other applications for these chiral sulfoximines or sulfilimines.

\section{Conclusion}

A wide range of racemic perfluorinated sulfilimines was separated by SFC, fully

\section{Acknowledgments}

Thanh-Nghi Le is grateful to the Vietnamese Government, the National Institute of Medicinal Materials in Hanoi for a doctoral fellowship. Yohan Macé is acknowledged for seminal experiments and Lucy Cooper for improvement of the English manuschript.

Received: March 27, 2014

[1] a) C. Bolm in 'Asymmetric Synthesis with Chemical and Biological Methods', Ed. D. Enders, K.-E. Jaeger, Wiley-VCH, Weinheim, 2007, p. 149; b) C. Worch, A. C. Mayer, C. Bolm in 'Organosulfur Chemistry in Asymmetric Synthesis', Ed. T. Toru, C. Bolm, Wiley-VCH, Weinheim, 2008, p. 209.

[2] Selected examples on the application of sulfoximine in synthesis: a) H.-J. Gais, Heteroat. Chem. 2007, 18, 472; b) E. B. Benetskiy, C. Bolm, Tetrahedron: Asymm. 2011, 22, 373; c) O. García Mancheño, J. Dallimore, A. Plant, C. Bolm, Adv. Synth. Catal. 2010, 352, 309; d) M. Frings, I. Atodiresei, Y. Wang, J. Runsink, G. Raabe, C. Bolm, Chem. Eur. J. 2010, 16, 4577; e) M. Frings, C. Bolm, Eur. J. Org. Chem. 2009, 4085; f) M. Lejkowski, P. Banerjee, G. Raabe, J. Runsink, H.-J. Gais, Eur. J. Org. Chem. 2014, 529; g) V. Mahajan, H.-J. Gais, Chem. Eur. J. 2011, 17, 6187; h) F. Lemasson, H.-J. Gais, J. Runsink, G. Raabe, Eur. J. Org. Chem. 2010, 2157; i) S. Acikalin, G. Raabe, J. Runsink, H.-J. Gais, Eur. J. Org. Chem. 2011, 5991.

[3] a) U. Lücking, Angew. Chem. Int. Ed. 2013, 52, 9399; b) Y. Min, C.-Q. Mao, S. Chen, G. Ma, J. Wang, Y. Liu, Angew. Chem. Int. Ed. 2012, 51, 6742; c) T. C. Sparks, G. B. Watson, M. R. Loso, C. Geng, J. M. Babcock, J. D. Thomas, Pesticide Biochem. Physiol. 2013, 107, 1; d) G. Siemeister, U. Lücking, A. M. Wengner, P. Lienau, W. Steinke, C. Schatz, D. Mumberg, K. Ziegelbauer, Mol. Cancer Ther. 2012, 11, 2265.

[4] For reviews see: a) M. Reggelin, C. Zur, Synthesis 2000, 1; b) H. Okamura, C. Bolm, Chem. Lett. 2004, 33, 482; c) M. Harmata, Chemtracts: Org. Chem. 2003, 16, 660; d) C. R. Johnson, Acc. Chem. Res. 1973, 6, 341; selected examples: e) F. Collet, R. H. Dodd, P. Dauban, Org. Lett. 2008, 10, 5473; f) J. Wang, M. Frings, C. Bolm, Angew. Chem. Int. Ed. 2013, 52, 8661; g) G. Y. Cho; C. Bolm, Org. Lett. 2005, 7, 4983; h) M. Ochiai, M. Naito, K. Miyamoto, S. Hayashi, W. Nakanishi, Chem. Eur. J. 2010, 16 , 8713; i) O. Garcìa Mancheño; C. Bolm, Chem. Eur. J. 2007, 13, 6674.

[5] a) G. K. S. Prakash, J. Hu, Acc. Chem. Res. 2007, 40, 921; b) S. Noritake, N. Shibata, S. Nakamura, T. Toru, M. Shiro, Eur. J. Org. Chem. 2008, 3465; c) G. K. S. Prakash, Z. Zhang, F. Wang, C. Ni, G. A. Olah, J. Fluorine Chem. 2011, 132, 792; d) W. Zhang, F. Wang, J. Hu, Org. Lett. 2009, 11, 2109; e) C. Urban, F. Cadoret, J. Blazejewski, E. Magnier, Eur. J. Org. Chem. 2011, 4862; f) Y. Nomura, E. Tokunaga, N. Shibata, Angew. Chem. Int. Ed. 2011, 50, 1885; g) Y.-D. Yang, X. Lu, G. Liu, E. Tokunaga, S. Tsuzuki, N. Shibata, Chemistry Open 2012, 1, 221; h) T. Luo, R. Zhang, W. Zhang, X. Shen, T. Umemoto, J. Hu, Org. Lett. 2014, 16, 888 ; i)W. Zhang, J. Hu, Adv. Synth. Catal. 2010, 352, 2799; j) X. Shen, M. Zhou, C. Ni, W. Zhang, J. Hu, Chem. Sci. 2014, 5, 117; h) Y. Macé, E. Magnier Eur. J. Org. Chem. 2012, 2479; i) V. Bizet, R. Kowalczyk, C. Bolm Chem. Soc. Rev. 2014, 43, 2426.

[6] a) R. Kowalczyk, A. J. F. Edmunds, R. G. Hall, C. Bolm, Org. Lett. 2011, 13, 768; b) N. V. Kondratendo, O. A. Radchenko, L. M. Yagupolskii, Zh. Org. Khim. 1984, 2250; c) E. Magnier, C. Wakselman, Synthesis 2003, 565; 
d) M. L. Boys, E. W. Collington, H. Finch, S. Swanson, J. F. Whitehead, Tetrahedron Lett. 1988, 29, 3365; e) W. Zhang, W. Huang, J. Hu Angew. Chem. Int. Ed. 2009, 48, 9858; f) Y. Mace, B. Pégot, R. Guillot, C. Bournaud, M. Toffano, G. Vo-Thanh, E. Magnier, Tetrahedron 2011, 67, 7575; g) Y. Mace, C. Constant-Urban, S. Bouvet, B. Pégot, C. Bournaud, M. Toffano, G. Vo-Thanh, P. Diter, E. Magnier, Synthesis 2013, 45,1505 .

[7] a) M. Kahraman, S. Sinishtaj, P. M. Dolan, T. W. Kensler, S. Peleg, U. Saha, S. S. Chuang, G. Bernstein, B. Korczak, G. H. Posner, J. Med. Chem. 2004, 47, 6854; b) X. Shen, W. Zhang, L. Zhang, T. Luo, X. Wan, J. Hu, Angew. Chem. Int. Ed. 2012, 51, 6966; c) X. Shen, W. Miao, C. Ni, J. Hu, Angew. Chem. Int. Ed. 2014, 53, 775.

[8] X. Shen, W. Zhang, C. Ni, J. Hu, Y. Gu, J. Am. Chem. Soc, 2012, 134, 16999.

[9] A. V. Matsnev, N. V. Kondratenko, Y. L. Yagupolskii, L. M. Yagupolskii, Tetrahedron Lett. 2002, 43, 2949

[10] H. Srour, P. Le Maux, S. Chevance, G. Simonneaux, Coord. Chem. Rev. 2013, 257, 3030.

[11] J.-L. Brunel, P. Diter, M. Duetsch, H. B. Kagan, J. Org. Chem. 1995, 60, 8086.

[12] a) F. Di Furia, G. Licini, G. Modena,
Tetrahedron Lett. 1989, 30, 2575; b) V. Conte, F. Di Furia, G. Licini, G. Modena, Tetrahedron Lett. 1989, 30, 4859.

[13] K. K. Andersen, W. Gaffield, N. E. Papanikolaous, J. W. Foley, R. I. Perkin, J. Am. Chem. Soc. 1964, 86, 5637.

[14] G. K. S. Prakash, A. K. Yudin, Chem. Rev. 1997, 97, 757.

[15] a) F. Rebiere, O. Samuel, L. Ricard, H. B. Kagan, J. Org. Chem. 1991, 56, 5991; b) H B. Kagan, P. Diter, A. Gref, D. Guillaneux, A. Masson-Szymczak, F. Rebiere, O. Riant, O. Samuel, S. Taudien, Pure \& Appl. Chem. 1996, $68,29$.

[16] a) K. Matsumara, H. Fujihara, J. Org. Chem. 1991, 56, 6341; b) L. Girodier, C. Maignan, F. Rouessac, Tetrahedron: Asymm. 1992, 3, 857.

[17] G. Solladié, J. Hutt, A. Girardin, Synthesis 1987, 173.

[18] F. Faigl, E. Fogassy, M. Nogradi, E. Palovics, J. Schindler, Tetrahedron: Asymm. 2008, 19, 519.

[19] J. Brandt, H.-J. Gais, Tetrahedron: Asymm. 1997, 8, 909 .

[20] a) Separation conditions for trifluoromethyl phenylsulfoxide: Chiralcel IB column 250 $\mathrm{mm} \times 4.6 \mathrm{~mm}$ (thermostatted column $20{ }^{\circ} \mathrm{C}$ ); elution with a mixture of hexane /isopropanol 90/10; flow rate $0.7 \mathrm{~mL} / \mathrm{min}$.; retention time 6.8 min. and $7.1 \mathrm{~min}$; b) Separation conditions for sulfilimines 5a and 5b: Chiralpak IB column 250 $\mathrm{mm} \times 4.6 \mathrm{~mm}$ (thermostatted column $20{ }^{\circ} \mathrm{C}$ ); elution with a mixture of hexane/isopropanol $75 / 25$; flow rate $0.7 \mathrm{~mL} / \mathrm{min}$; r retention time 7.3 $\mathrm{min}$. for $(S)$ - and $10.0 \mathrm{~min}$. for $(R)$-enantiomer; c) Separation conditions for sulfoximines $\mathbf{6 a}$ and 6b: Chiralcel OJ-H column $250 \mathrm{~mm} \times 4.6$ $\mathrm{mm}$ (thermostatted column $20^{\circ} \mathrm{C}$ ); elution with a mixture of hexane /isopropanol $75 / 25$; flow rate $0.7 \mathrm{~mL} / \mathrm{min}$.; retention time $14.7 \mathrm{~min}$. for $(S)$ - and $18.5 \mathrm{~min}$. for $(R)$-enantiomer.

[21] a) K. L. Williams, L. S. Sander, J. Chromatogr. A. 1997, 785, 149; b) W. Ren-Qi, O. Teng-Teng, T. Weihua, Ng Siu-Choon, TrAC Trends in Analytical Chemistry 2012, 37, 83.

[22] Separation conditions for sulfilimines $\mathbf{5 a}$ and 5b: Chiralpak IA column $250 \mathrm{~mm} \times 20 \mathrm{~mm}$; elution with $5 \%$ methanol in $\mathrm{CO}_{2}$; flow rate 10.0 $\mathrm{mL} / \mathrm{min}$.; 100 bar as back pressure regulation; column oven at $30{ }^{\circ} \mathrm{C}$; retention time $22.8 \mathrm{~min}$. for $(S)$ - and $24.6 \mathrm{~min}$. for $(R)$-enantiomer.

[23] CCDC 986644-986645 contains the supplementary crystallographic data for this paper. These data can be obtained free of charge from the Cambridge Crystallographic Data Centre via http://www.ccdc.cam.ac.uk/Community/ Requestastructure. 